\title{
Study of the Antimicrobial Profile and Phytochemical Composition of Solvent Extracts of Leaves and Female Cones of Cycas revoluta
}

\author{
Kishori Lal $^{1 *}$, Nafeesh Ahmed ${ }^{2}$ and Abhishek Mathur ${ }^{3}$ \\ ${ }^{1}$ Department of Microbiology, CMJ University, Shillong, Meghalaya, India \\ ${ }^{2}$ Department of Botany, Forest Research Institute (FRI), Dehradun (U.K), India \\ ${ }^{3}$ NCFT, New Delhi, India \\ *Corresponding author
}

\section{A B S T R A C T}

\section{Keywords \\ Cycas revoluta, Leaves, Female cones, Hydro- alcoholic, Chloroformic solvent extracts \\ Article Info \\ Accepted: \\ 20 March 2017 \\ Available Online: \\ 10 April 2017}

In the ethno-pharmacological approach, local knowledge about the potential uses of the plants is very useful as compared to the random approach where indigenous knowledge is not taken into consideration. Phytochemicals produced in plants are secondary compounds responsible for metabolic activities and defense in purpose. Phytochemicals are produced by specific biochemical pathways, which occur inside the plant cells. The gymnosperm, Cycas revoluta is a natural companion for palms, working well as under planting or in the foreground. In the present investigation, the chloroformic and hydro-alcoholic extracts of leaves and female cones of Cycas revoluta were screened for its antimicrobial potential and in urge for isolation and characterization of the potent molecule responsible for antimicrobial potential against pathogenic and drug resistant strains. The results showed that both the leaves and female cones of Cycas revoluta are potent antimicrobial agents. It was found that chloroformic extracts of the cones was having potent antimicrobial activity in comparison to the chloroformic extracts of leaves. The extracts were found to be promising antimicrobial agent against methicillin resistant Staphylococcus aureus (MRSA), E. coli, Salmonella abony, Aspergillus niger, Candida albicans and other pathogens reported in the study.

\section{Introduction}

Plants have served as a source of new pharmaceutical products and inexpensive starting materials for the synthesis of some known drugs. Components with medicinal properties from plants play an important role in conventional Western medicine. In 1984, at least $25 \%$ of the Western medicine issued in the US and Canada were derived from or modelled after plant natural products and 119 secondary metabolites were used globally as drugs (Farnsworth, 1994). It has been estimated that $14-28 \%$ of higher plant species are used medically. Only $15 \%$ of all angiosperms have been investigated chemically and $74 \%$ of pharmaceutically active plant derived components were discovered after following up on ethno medical use of the plant (Farnsworth, 1991). The value of ethno-medicine and traditional pharmacology is nowadays gaining increasing recognition in modern medicine because the search for new potential medicinal plants is frequently based on an ethno-medicinal basis (Hasan et al., 2009; Prajapati, 2002; Jaradat et 
al., 2004). Different pharmacological properties from plants of North west Himalaya Garhwal region were determined (Mathur et al., 2010a,b; 2011a,b). In the ethno-pharmacological approach, local knowledge about the potential uses of the plants is very useful as compared to the random approach where indigenous knowledge is not taken into consideration. Different polycrystalline ferroelectric materials were investigated for antimicrobial and pharmacological properties (Heravi et al., 2016). The current study was performed in order to assess the antimicrobial properties of solvent extracts of leaves and female cones of Cycas revoluta, a common gymnosperm in lieu of isolation of antimicrobial polycrystalline ferroelectric materials.

\section{Materials and Methods}

\section{Plant materials}

The leaves and female cones of the plant, Cycas revoluta (Sago-Palm) were collected from the local gardens of Forest Research Institute (FRI), Dehradun. The materials of the plant were taxonomically identified by Botanists/Taxonomists. Records of the specimens were deposited in FRI, Dehradun for future reference.

\section{Chemicals}

Analytical reagent (AR) grade ethanol and chloroform were purchased from Ranchem Pvt. Ltd., India. Nutrient agar/broth and Sabouraud's Dextrose agar/broth were purchased from Hi Media Pvt. Ltd., Mumbai, India. Positive controls, Erythromycin and Fucanazole were obtained as the gift samples from Ranbaxy Pvt. Ltd., India.

\section{Preparation of plant extracts}

The leaves and female cones of the plant were separated, washed with distilled water, dried under shade and pulverized. The method of Alade and Irobi (1993) was adopted for preparation of plant extracts with little modifications. Briefly $20 \mathrm{~g}$ portions of the powdered plant material were soaked separately in different solvents viz. hydroalcohol $(50 \% \mathrm{v} / \mathrm{v})$ and chloroform on the basis of decreasing polarity for $72 \mathrm{~h}$. Each mixture was stirred every $24 \mathrm{~h}$ using a sterile glass rod. At the end of extraction, each solvent was passed through Whatmann filter paper No. 1 (Whatmann, England). The filtrates obtained were later concentrated in vacuo using water bath at $30{ }^{\circ} \mathrm{C}$.

\section{Determination of antimicrobial activity}

\section{Culture media}

For antibacterial and antifungal activities, Nutrient agar/broth and Sabouraud's dextrose agar/broth respectively was procured from $\mathrm{Hi}$ Media Pvt. Bombay, India.

\section{Inoculum}

The bacteria were inoculated into Nutrient broth and incubated at $37^{\circ} \mathrm{C}$ for $18 \mathrm{~h}$ and suspension was checked to provide approximately, $10^{5} \mathrm{Cfu} / \mathrm{ml}$. The same procedure was done for fungal strains and there strains were inoculated into Sabouraud's dextrose broth but the fungal broth cultures were incubated at $48-72 \mathrm{~h}$.

\section{Microorganisms used}

Pure cultures of various pathogenic bacterial and fungal strains, E. coli NCIM 2065, Lactobacillus plantarum NCIM 2083, Micrococcus luteus ATCC 9341, Salmonella abony NCIM 2257, Candida albicans NCIM 3471, Aspergillus niger NCIM 1196 and Methicillin resistant strains of Staphylococcus aureus (MRSA) 101 Staphylococcus aureus (MRSA) 102 isolated from clinical specimens 
viz. pus and blood respectively of infected patients were procured with authentication for the study.

Determination of diameter of zone of inhibition by well diffusion method

The agar well diffusion method (Perez et al., 1993) was modified. Nutrient agar medium (NAM) was used for bacterial cultures while Sabouraud's dextrose agar/broth was used for the growth of fungal cultures. The culture medium was inoculated with the bacteria separately suspended in nutrient broth while the culture medium was inoculated with the fungus separately suspended in Sabouraud's dextrose broth.

A total of $8 \mathrm{~mm}$ diameter wells were punched into the agar and filled separately with leaves and female cones extract $(1 \mathrm{~g} / \mathrm{ml})$ and solvent blanks. Solvents, chloroform and hydroalcohol were used as negative controls. Standard antibiotic (Erythromycin, $1 \mathrm{mg} / \mathrm{ml}$ ) was simultaneously used as the positive control. The plates were then incubated at $37^{0} \mathrm{C}$ for $18 \mathrm{~h}$.

The antibacterial activity was evaluated by measuring the diameter of zone of inhibition observed. For assaying, antifungal activity of plant extracts, Sabouraud's dextrose agar/broth medium plates were used. The same procedure as that for determination of antibacterial property was adopted and then after, the diameter of zone of inhibition was observed after 48-72 h. Fucanazole $(1 \mathrm{mg} / \mathrm{ml})$ was used as standard for determination of antifungal activity. The procedure for assaying antibacterial and antifungal activity was performed in triplicates to confirm the readings of diameter of zone of inhibition observed for each of the test organism. The pure compound isolated was further assayed for antimicrobial activity by the above method.

\section{Determination of Minimum Inhibitory Concentration (MIC)}

MIC value of potent plant extracts was determined by the method adopted by Vollekova et al., (2001) and Usman et al., (2007), with some modifications. Plant extract was prepared in highest concentration $(1 \mathrm{~g} / \mathrm{ml})$ in sterile distilled water and was serially diluted with $\mathrm{N}$-saline $(0.85 \% \mathrm{NaCl})$ and similar quantity of bacterial/fungal suspension was added to different test tubes and incubated for $48 \mathrm{~h}$. The inhibition of turbidity appeared in the minimum dose at which total growth of bacteria gets killed is known as minimum lethal concentration (MLC) while little turbidity appeared in the minimum amount of dose of plant extract which inhibits the growth of bacteria is known as Minimum Inhibitory Concentration (MIC).

\section{Phytochemical screening of the extracts}

The portion of the dry extracts was subjected to the Phytochemical screening using the method adopted by Trease and Evans (1989) and Harbourne (1983). Phytochemical screening was performed to test for alkaloids, saponin, tannins, flavanoids, steroids, sugars, cardiac glycosides and anthraquinones (Sofowora, 1993).

\section{Test for alkaloids}

The $0.5 \mathrm{~g}$ of the plant extract was dissolved in $5 \mathrm{ml}$ of $1 \% \mathrm{HCl}$ and was kept in water bath for about 2 minutes. $1 \mathrm{ml}$ of the filtrate was treated with Wagner's reagent. Reddish orange colored turbidity or precipitation was taken as indicator for the presence of alkaloids.

\section{Test for tannins}

About $0.5 \mathrm{~g}$ of the sample was dissolved in 10 $\mathrm{ml}$ of boiling water and was filtered. Few $\mathrm{ml}$ 
of $6 \% \mathrm{FeCl}_{3}$ was added to the filtrate. Deep green color appeared confirmed the presence of Tannins (Trease and Evans, 1989).

\section{Test for flavanoids}

About $0.2 \mathrm{gm}$ of the extract was dissolved in methanol and heated for some time. A chip of mg metal was introduced followed by the addition of few drops of conc. $\mathrm{HCl}$. Appearance of red or orange color was Indicator of the flavanoids.

\section{Test for saponin}

About $0.5 \mathrm{~g}$ of the plant extract was stirred with water in the test tube. Frothing persists on warming was taken as an evidence for the presence of saponin.

\section{Test for steroids}

Salkowski's method was adopted for the detection of steroids. About $0.5 \mathrm{~g}$ of extract was dissolved in $3 \mathrm{ml}$ of chloroform and filtered. To the filtrate, conc. $\mathrm{H}_{2} \mathrm{SO}_{4}$ was added to form a lower layer. Reddish brown color was taken as positive for the presence of steroids ring (Agarwal et al., 2011).

\section{Test for cardiac glycosides}

About $0.5 \mathrm{~g}$ of the extract was dissolved in 2 $\mathrm{ml}$ of glacial acetic acid containing 1 drop of $1 \% \mathrm{FeCl}_{3}$. This was under laid with concentrated $\mathrm{H}_{2} \mathrm{SO}_{4}$. A brown ring obtained at the interphase indicates the presence of deoxy sugar. A violet ring appeared below the ring while in the acetic acid layer a greenish ring appeared just above ring and gradually spread throughout this layer.

\section{Test for reducing sugars}

One ml each of Fehling's solutions, I and II was added to $2 \mathrm{ml}$ of the aqueous solution of the extract. The mixture was heated in a boiling water bath for about 2-5 minutes. The production of a brick red precipitate indicated the presence of reducing sugars.

\section{Test for anthraquinones}

$5 \mathrm{ml}$ of the extract solution was hydrolyzed with dil/conc. $\mathrm{H}_{2} \mathrm{SO}_{4} .1 \mathrm{ml}$ of dilute ammonia was added to it. Rose pink colour confirmed the presence of anthraquinones.

\section{Results and Discussion}

The present study suggests that, the leaves and female cones of predominant gymnosperm, Cycas revoluta (Sago Palm) after identification and authentication were collected from high altitudes of North West Himalaya Garhwal region. It is already understood that, angiosperms are the predominant source of medicinal molecules which shows variable pharmacological action but any how less study has been done on gymnosperms (naked seeded/non flowering plants).

The information about general medicinal properties of Sago palm taken for the study was obtained from local/traditional healers of Uttarakhand. These female cones and leaves are used in Ayurveda as medicines but not much work has been emphasized to reveal their socio-economic importance, the active molecules responsible in these parts for treatment of pathogenic diseases and as food supplements in the form of antioxidants. The present brief study was thus initiated to reveal some of the pharmaceutical properties of leaves and female cones of Cycas revoluta (Sago Palm) having abundance on high altitudes in Uttarakhand valley. The present investigation leads to the isolation and identification of the compounds from the potent extracts which can be utilized as antimicrobials and antioxidants. 


\section{Antimicrobial activity of solvent extracts}

In the present investigation, hydro-alcoholic and chloroformic extracts of leaves and chloroformic extracts (only) of cones of Cycas revoluta were screened for their antimicrobial potential against pathogenic bacterial and fungal strains along with methicillin resistant strains of Staphylococcus aureus. The results were found to be very interesting. It was found that chloroformic extracts of female cones and leaves of the plant were potent antimicrobial agents in comparison to hydro-alcoholic extracts.

It was found that hydro-alcoholic and chloroformic extracts of leaves of the plant showed potent antibacterial activity against bacterial strains studied viz. Lactobacillus plantarum NCIM 2083, Micrococcus luteus ATCC 9341, Salmonella abony NCIM 2257, MRSA 101 and MRSA 102 while there was no antibacterial potential found against $E$. coli NCIM 2065. The extracts also not showed any significant antifungal activity. It was found that E. coli NCIM 2065, Candida albicans NCIM 3471, Aspergillus niger NCIM 1196 and Methicillin resistant strains of Staphylococcus aureus (MRSA) were resistant against these solvent extracts. Although, slight antifungal activity was found of chloroformic extract against Aspergillus niger NCIM 1196 (Sharma et al., 2014). The results are shown in table 1 and figure 1.

The chloroformic extracts of cones were much more effective against all the pathogens studied in comparison to chloroformic and hydro-alcoholic extracts of leaves. The results showed that chloroformic extracts of cones were significant antimicrobial agent against all the pathogens studied viz. E. coli NCIM 2065, Lactobacillus plantarum NCIM 2083, Micrococcus luteus ATCC 9341, Salmonella abony NCIM 2257, Candida albicans NCIM 3471, Aspergillus niger NCIM 1196 and Methicillin resistant strains of Staphylococcus aureus (MRSA). The results were found to be more surprising when the extracts were found to have significant antibacterial activity against MRSA strains (isolated from pus and blood). Almost similar pattern of antifungal activity of cone chloroformic extracts was found against fungal strains studied viz. Candida albicans NCIM 3471, Aspergillus niger NCIM 1196. The results are shown in table 2 and figure 2.

Table.1 Antimicrobial activities of leaves extracts of Cycas revolute

\begin{tabular}{|c|c|c|c|c|c|c|c|c|}
\hline $\begin{array}{c}\text { Solvent extracts } \\
\text { of leaves }\end{array}$ & \multicolumn{7}{|c|}{ Diameter of zone of inhibition (mm) } \\
\cline { 2 - 9 } & E. coli & S. abony & M. luteus & L. plantarum & MRSA- 101 & MRSA-102 & A. niger & C. albicans \\
\hline $\begin{array}{c}\text { Hydro-alcoholic } \\
\text { extracts (1 } \\
\text { mg/ml) }\end{array}$ & NA & 27.5 & 23.0 & 28.0 & 10.0 & 18.0 & NA & NA \\
\hline $\begin{array}{c}\text { Chloroformic } \\
\text { extracts (1 } \\
\text { mg/ml) }\end{array}$ & NA & 22.2 & 33.0 & 25.0 & 7.0 & 12.0 & 7.0 & NA \\
\hline $\begin{array}{c}\text { Erythromycin } \\
(1 \mathrm{mg} / \mathrm{ml})\end{array}$ & 10 & 25.0 & 25.0 & 22.0 & 12.0 & 15.0 & NT & NT \\
\hline $\begin{array}{c}\text { Fucanazole } \\
(1 \mathrm{mg} / \mathrm{ml})\end{array}$ & NT & NT & NT & NT & NT & NT & 24.0 & 20.0 \\
\hline
\end{tabular}

*NA, No Activity; NT, Not Tested; MRSA, Methicillin resistant S. aureus 
Table.2 Antimicrobial activities of female cones extracts of Cycas revoluta

\begin{tabular}{|c|c|c|c|c|c|c|c|c|}
\hline \multirow{3}{*}{$\begin{array}{l}\text { Solvent extracts } \\
\text { of female cones }\end{array}$} & \multicolumn{8}{|c|}{ Diameter of zone of inhibition (mm) } \\
\hline & \multicolumn{8}{|c|}{ Pathogens studied } \\
\hline & E. coli & $\begin{array}{c}S . \\
\text { abony }\end{array}$ & $\begin{array}{c}\text { M. } \\
\text { luteus }\end{array}$ & $\begin{array}{c}L . \\
\text { plantarum }\end{array}$ & $\begin{array}{c}\text { MRSA } \\
101\end{array}$ & $\begin{array}{c}\text { MRSA } \\
102\end{array}$ & niger & C. albicans \\
\hline $\begin{array}{c}\text { Hydro-alcoholic } \\
\text { extracts } \\
(1 \mathrm{mg} / \mathrm{ml})\end{array}$ & NA & 18.0 & 22.0 & 12.0 & 12.0 & NA & NA & NA \\
\hline $\begin{array}{l}\text { Chloroformic } \\
\text { extracts } \\
(1 \mathrm{mg} / \mathrm{ml})\end{array}$ & 27.0 & 23.0 & 22.0 & 15.0 & 23.0 & 27.0 & 23.0 & 22.0 \\
\hline $\begin{array}{c}\text { Erythromycin } \\
(1 \mathrm{mg} / \mathrm{ml})\end{array}$ & 21.0 & 25.0 & 25.0 & 17.0 & 13.0 & 26.0 & NT & NT \\
\hline $\begin{array}{c}\text { Fucanazole } \\
(1 \mathrm{mg} / \mathrm{ml})\end{array}$ & NT & NT & NT & NT & NT & NT & 24 & 20.0 \\
\hline
\end{tabular}

*NA, No Activity; NT, Not Tested; MRSA, Methicillin resistant S. aureus

Table.3 MIC and MLC values of potent extracts of Cycas revoluta

\begin{tabular}{|c|c|c|c|}
\hline Solvent Extracts & Against Pathogen & MIC (mg/ml) & MLC (mg/ml) \\
\hline Chloroformic leaves extract & Aspergillus niger & 0.01 & 0.1 \\
\hline Chloroformic leaves extract & Micrococcus luteus & 0.01 & 0.1 \\
\hline Chloroformic cones extract & Aspergillus niger & 10 & 12 \\
\hline Chloroformic cones extract & Salmonella abony & 10 & 12 \\
\hline
\end{tabular}

Table.4 Phytochemical screening of the active constituents

\begin{tabular}{|c|c|c|c|c|c|c|c|c|}
\hline Extracts & Alkaloids & Tannins & Flavanoids & Saponin & Steroids & $\begin{array}{c}\text { Cardiac } \\
\text { glycosides }\end{array}$ & $\begin{array}{c}\text { Reducing } \\
\text { sugars }\end{array}$ & Anthraquinones \\
\hline $\begin{array}{c}\text { Cones } \\
\text { extracts }\end{array}$ & - & - & + & + & + & - & + & - \\
\hline $\begin{array}{c}\text { Leaves } \\
\text { extracts }\end{array}$ & + & - & - & + & - & - & + & - \\
\hline
\end{tabular}

$*_{-}$, Absent; +, Present 
Figure.1 Antimicrobial activities of leaves extracts of Cycas revolute

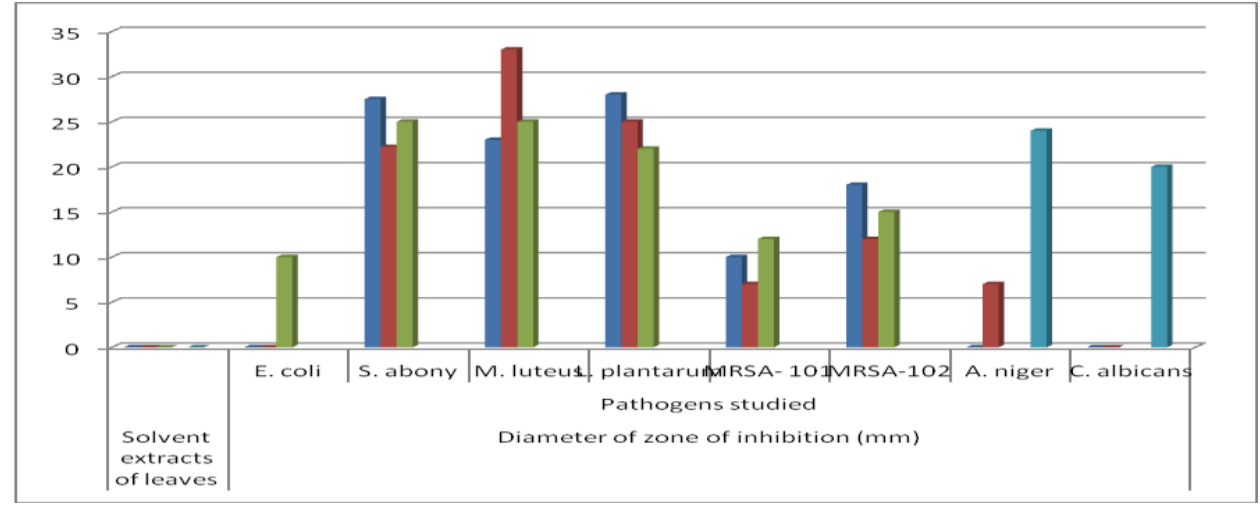

Figure.2 Antimicrobial activities of female cones extracts of Cycas revolute

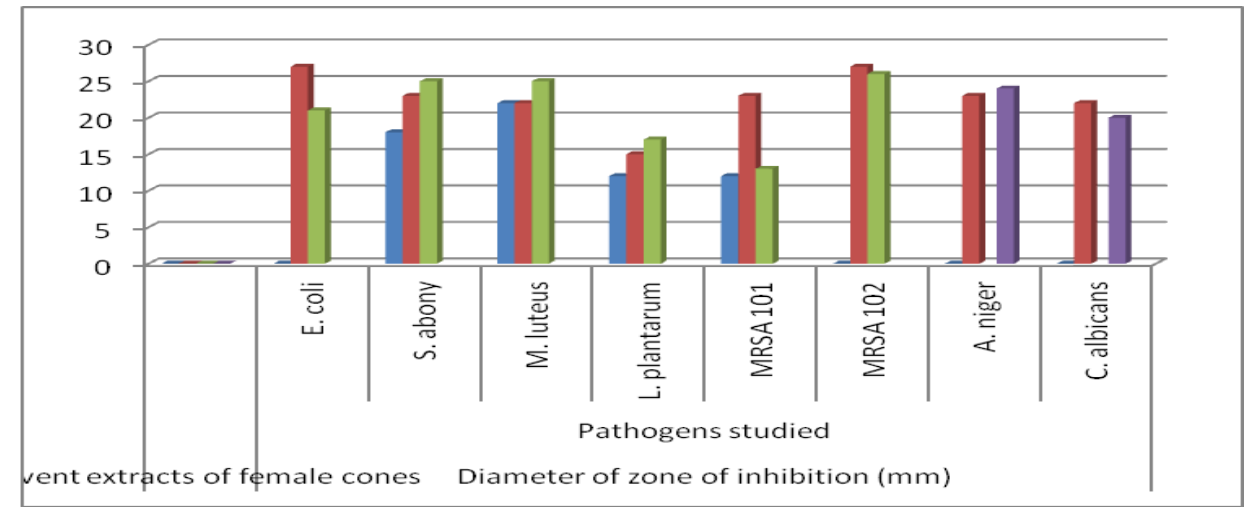

Figure.3 MIC and MLC values of potent extracts of Cycas revolute

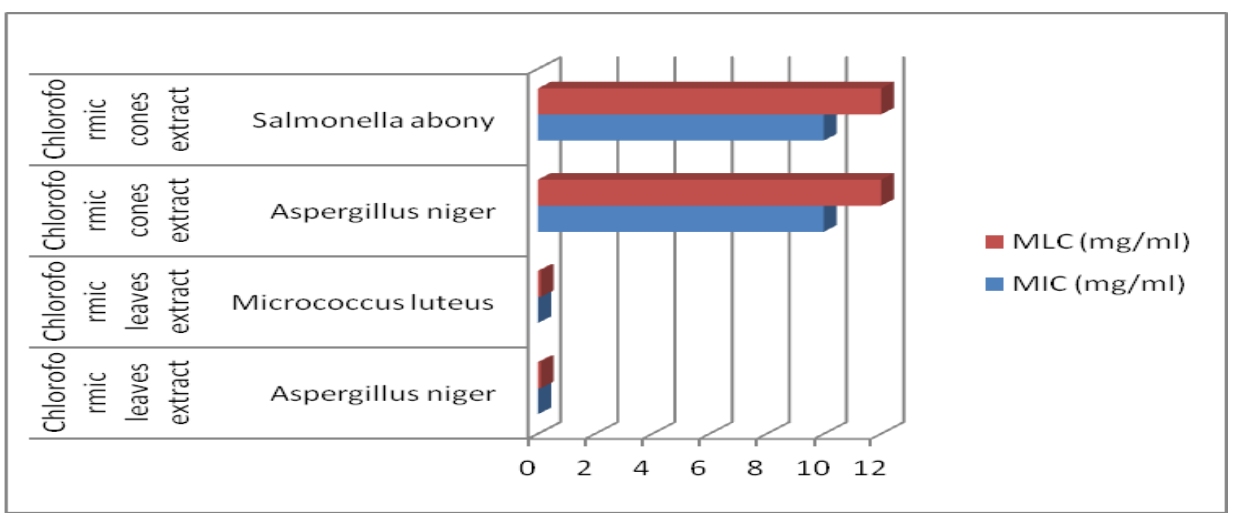

Minimum Inhibitory Concentration (MIC) of solvent extracts

The female cones and leaves chloroformic extracts of Cycas revoluta were subjected for determination of MIC and MLC values. The extracts were serially diluted with $\mathrm{N}$-saline and MIC values were determined along with MLC values against the pathogens which were found to be most sensitive against the same. MIC and 
MLC values were determined of chloroformic leaves extract against Aspergillus niger NCIM 1196 and Micrococcus luteus ATCC 9341 while in case of cones chloroformic extract, values were determined against Aspergillus niger NCIM 1196 and Salmonella abony NCIM 2257. The results revealed that chloroformic extracts of leaves of the plant showed MIC and MLC values, $0.01 \mathrm{mg} / \mathrm{ml}$ and $0.1 \mathrm{mg} / \mathrm{ml}$ respectively against Micrococcus luteus ATCC 9341 and Aspergillus niger NCIM while chloroformic cone extracts of the plant showed MIC and MLC values, $10 \mathrm{mg} / \mathrm{ml}$ and $12 \mathrm{mg} / \mathrm{ml}$ against Salmonella abony NCIM 2257 and Aspergillus niger NCIM 1196. The results are shown in table 3 and figure 3.

\section{Phytochemical Screening of the potent extracts}

The chloroformic and hydro-alcoholic extracts of the leaves were subjected to phytochemical screening in lieu of determination of active constituents present in the extracts. It was observed that, flavanoids, saponin, steroids and reducing sugars were present in chloroformic extracts of cones while alkaloids, saponin and reducing were present in chloroformic extract of leaves. The results are shown in table 4 .

The studies are in correlation with the findings reported by Sharma and Mathur (2014, 2015). In the previous study performed, the potent molecule isolated from Cycas revoluta was a flavone.

\section{Statistical analysis}

The data recorded from various in vitro and laboratory experiments were subjected to statistical analysis. The differences exhibited by treatments in various experiments were tested for their significance at 5 per cent using standard procedure as described (Gomez and Gomez, 1983).

In conclusion the study highlighted the importance of pharmacological activities viz. antimicrobial and antioxidant activities of leaves and female cones of Cycas revoluta. The preparation of hydro-alcoholic and chloroformic extracts of leaves and female cones of Cycas revoluta through forward or activity directed approach was emphasized upon and successfully demonstrated in the present study lead to bioactive pharmacological agents which can be utilized as potent antimicrobial molecules. The study makes a strong plea in favor of proper investigation of plant kingdom to generate molecules having variable pharmacological properties. The scope of utilizing plant bioactive(s) in treating infectious diseases, is validated as per the studies concerned.

\section{Acknowledgement}

The authors are thankful to Head, Department of Botany, Forest Research Institute (FRI), Dehradun (U.K), India for providing necessary facilities during the experiment.

\section{References}

Agarwal A, Singhvi IJ, Bele D, Sharma K, Gupta SK, Karwani G, Kumawat M. 2011. Evaluation of steroids in face creams of different marketed brands. International J. Pharmacy \& Technology, 3(2): 2480-2486.

Alade PI, Irobi ON. 1993. Antimicrobial activities of crude leaf extracts of Acalypha wilkensiana. Journal of Ethnopharmacology, 39: 171-174.

Farnsworth NR, Soejarto DD. 1991. Global importance of medicinal plants: Conservation of medicinal plants, Cambridge University Press, Cambridge, pp. 25-51.

Farnsworth NR. 1994. Ethnopharmacology and drug development. Ethnobotany and search for new drugs, 42-59.

Gomez K A and Gomez A A. 1983. Statistical Procedures for Agricultural Research. $2^{\text {nd }}$ edition. John Willey and Sons Inc, New York, USA. 680 p.

Harborne, J.B. 1973. Phytochemical methods. A guide to modern techniques of plant analysis, 2nd edition Chapmann and 
Hall, 1973, London, pp. 140-149.

Hasan SZ, Mishra V, Singh S, Arora G, Sharma S, Sharma S. 2009. Current status of herbal drugs and their future perspectives. Biological Forum, 1(1): 12-17.

Heravi F, Bagheri H, Rangrazi A, Zebarjad SM. 2016. Effects of the addition of the casein phosphor-peptide- amorphous calcium phosphate on mechanical properties of luting and lining glass monomer cement. Materials Research Express, 3 (7).

Jaradat N, Sweileh W, Kerki S. 2004. Pharmacological investigation of plant derived pharmaceuticals in Palestine. Al- Najah Univ. J. Res., 18(1): 81-86.

Mathur A, Dua VK, Prasad GBKS. 2010a. Antimicrobial activity of leaf extracts of Murraya koenigii against aerobic bacteria associated with Bovine mastitis. International Journal of Chemical, Environmental and Pharmaceutical Research, 1(1): 12-16.

Mathur A, Verma SK, Singh SK, Prasad GBKS, Dua VK. 2010b. Phytochemical investigation and in vitro antioxidant activities of some plants of Uttarakhand. IJPI's Journal of Pharmacogonasy and Herbal Formulations, 1(1): 1-7.

Mathur A, Prasad GBKS, Rao N, Babu P, Dua VK. 2011a. Isolation and identification of antimicrobial compound from Mentha piperita L. Rasayan Journal of Chemistry, 4(1): 36-42.

Mathur A, Verma SK, Singh SK, Mathur D, Prasad GBKS, Dua VK. 2011b. Investigation of anti-inflammatory properties of Swertia chirayta and Gloriosa superba. Recent Research in Science \& Technology, 3(3): 40-43.

Perez C, Anesini C. 1993. In vitro antimicrobial activity of Argentine folk medicinal plants against Salmonella typhi. Journal of Ethnopharmacology, 44: 41-46.

Prajapati MM. 2002. Study of plant community and study of ethnobotanical aspects of Shamlaji forests, hills and hillocks. Ph.D. thesis, North Gujarat University, Patan.

Sharma R., Katiyar, A., Mathur A. 2014. Screening of solvent extracts of Cycas revoluta for isolation of antimicrobial compound. Biolife, 2(4): 1218-1228.

Sharma R., Mathur A. 2015. Evaluation of antioxidant potential of solvent extracts of female cones and leaves of Cycas revoluta. World Journal of Pharmacy and Pharmaceutical Sciences, 4(1): 1466-1472.

Sofowora AO. 1993. Traditional Medicine and Medicinal Plants in Africa. $2^{\text {nd }}$ Ed., University of Life Press, pp. 320.

Trease GE, Evans WC. 1989. Pharmacogonasy, $14^{\text {th }}$ Edition, Brown Publication.

Usman $\mathrm{H}$, Abdulrahman $\mathrm{FI}$ and Ladan $\mathrm{AH}$. 2007. Phytochemical and antimicrobial evaluation of Tribulus terrestris L. (Zygophylaceae) growing in Nigeria. Res. J. Bio. Sci. Medwell Journals, 2(3): 244-247.

Vollekova AD, Kostalova, Sochorova R. 2001. Isoquinoline alkaloids from Mahonia aquifolium stem bark is active against Malassezia sp. Folia Microbiol., 46: 107-111.

\section{How to cite this article:}

Kishori Lal, Nafeesh Ahmed and Abhishek Mathur. 2017. Study of the Antimicrobial Profile and Phytochemical Composition of Solvent Extracts of Leaves and Female Cones of Cycas revoluta. Int.J.Curr.Microbiol.App.Sci. 6(4): 2514-2522. doi: https://doi.org/10.20546/ijcmas.2017.604.293 